\title{
Oral Microbiome of Children Living in an Isolated Area in Myanmar
}

\author{
Yoshiaki Nomura * , Ryoko Otsuka, Ryo Hasegawa and Nobuhiro Hanada \\ Department of Translational Research, Tsurumi University School of Dental Medicine, \\ Yokohama 230-8501, Japan; otsuka-ryoko@tsurumi-u.ac.jp (R.O.); hasegawakejp@gmail.com (R.H.); \\ hanada-n@tsurumi-u.ac.jp (N.H.) \\ * Correspondence: nomura-y@tsurumi-u.ac.jp; Tel.: +81-45-580-8462
}

Received: 5 May 2020; Accepted: 3 June 2020; Published: 5 June 2020

\begin{abstract}
Several studies have shown that the oral microbiome is related to systemic health, and a co-relation with several specific diseases has been suggested. The oral microbiome depends on environmental- and community-level factors. In this observational study, the oral microbiomes of children of isolated mountain people were analyzed with respect to the core oral microbiome and etiology of dental caries. We collected samples of supragingival plaque from children (age 9-13) living in the Chin state of Myanmar. After DNA extraction and purification, next-generation sequencing of the V3-V4 hypervariable regions of the 16S rRNA was conducted. From thirteen subjects, 263,458 valid reads and 640 operational taxonomic units were generated at a $97 \%$ identity cut-off value. At the phylum level, Proteobacteria was the most abundant, followed by Firmicutes and Bacteroides. Forty-four bacteria were detected in total from all the subjects. For children without dental caries, Proteobacteria was abundant. In contrast, in children with dental caries, Firmicutes and Bacteroides were abundant. The oral microbiome of children living in an isolated area may be affected by environmental- and community-level factors. Additionally, the composition of the oral microbiome may affect the risk of dental caries.
\end{abstract}

Keywords: oral microbiome; dental caries; children

\section{Introduction}

With the advancement of high throughput next-generation sequencing, data on the human oral microbiome has been accumulated. Conventionally, it has been suggested that 700 species of bacteria inhabit the oral cavity [1]. By employing high throughput sequencing, 19,000 phylotypes have been shown to inhabit the oral cavity, including uncultivable bacteria [2]. These bacteria have effects on a person's health status, especially their oral health. There are some reports that have compared the oral microbiome of subjects with the healthy and diseased oral states: periodontal disease and dental caries [3-5]. Additionally, imbalances of oral bacteria have an effect on a person's systemic health status [6-12]. There are several ecological niches in the oral cavity, which make the oral microbiome complex [1]. It is well-established that the composition of microbial communities varies in different parts of the oral cavity. The tongue, teeth, mucosa, plate and gingiva have distinctive profiles [13].

In this respect, the concept of a core oral microbiome has been proposed. The core microbiome is longitudinally stable, keeping the human body healthy $[14,15]$. However, ethnic- or community-level differences in the oral microbial profile have been proposed [16,17].

The prevalence of dental caries has declined across the world. However, it is still prevalent in developing countries. Subjects with rampant caries exist in these countries [1]. Myanmar is a multiracial nation and a developing country with more than 135 ethnic groups. Some of the ethnic groups live in alpine environments in isolation. In these areas, medical and dental supplies and 
oral care are insufficient. In Myanmar, the prevalence of dental caries is different in urban areas and rural areas. In urban areas, the prevalence of dental caries in children is high: $68.5 \%$ in fifth-grade students [18] and $53.2 \%$ at the age of 12 [19]. In rural areas, the prevalence of dental caries at the age of 12 has been reported to be $15 \%$ [20]. In rural areas, the oral hygiene status is still low; in one study, $61 \%$ of children at the age of 12 had never brushed their teeth, and had almost no chance of having sweet snacks or beverages. In rural areas, however, there are subjects with rampant caries [21]. Studies have shown that the overall microbial composition and structure, rather than any particular dominant species, such as Streptococcus mutans, can better characterize the cariogenicity of the oral biofilm [22-24].

Therefore, information on the oral microbiome of ethnic minorities may be valuable when considering the bacterial etiology of dental caries and ethnic-, environmental- and community-level differences in the oral microbiome. In this study, the oral microbiome of children of mountain people living in the Chin state of Myanmar was analyzed with respect to the core oral microbiome and etiology of dental caries. The aim of this study was to investigate specific oral microbiome profiles and specific species for the risk of dental caries in children living in isolated mountain areas.

\section{Materials and Methods}

\subsection{Subject}

The Government of Myanmar provides mobile and portable dental treatment services in isolated districts. Teams of dental staff from the Naypyidaw National Dental Hospital visit remote places. For children, an oral health checkup and oral hygiene instruction are provided, with local medical staff as translators. Fifty children attended the oral hygiene instruction lecture held at Tonzang on 24 December 2018.

Children with deciduous teeth were excluded. Thirteen children (9-13 years old) who had more than 15 permanent teeth were included in the analysis. Among them, seven children were caries-free while five children had dental caries. The number of dental caries (D) was $D=2: 3, D=3: 1$ and $D=4: 1$, respectively. No subjects had filled teeth or missing teeth due to dental caries.

\subsection{Oral Examination}

An oral examination was carried out at the Tonzang National Hospital. One dentist (R.O.) carried out the oral examination according to the guidelines provided by the World Health Organization. The definition and diagnosis of dental caries were based on the criteria of the World Health Organization [25]. The numbers of decayed teeth, teeth missing due to dental caries and filled teeth were recorded. The sum of decayed, missing and filled teeth was employed as a standardized index (DMF). In this study, no subject had missing or filled teeth, so DMF indicted the number of teeth with untreated dental caries.

\subsection{Sample Collection}

Supragingival plaque samples were collected as previously described [26,27]. Supragingival plaque samples were collected by tooth-brushing for $2 \mathrm{~min}$, followed by immersion of the toothbrush with the attached plaque in sterilized phosphate-buffered saline (PBS). Samples were kept on ice after finishing the examination, and were stored at $-20^{\circ} \mathrm{C}$. During transportation, samples were transported in an ice box with a refrigerant.

\subsection{Microbial DNA Extraction}

Dental plaque suspended in PBS was collected by centrifuging the sample at $3000 \mathrm{rpm}$ for $10 \mathrm{~min}$. DNA extraction was performed by the Maxwell 16 LEV Blood DNA Kit (Promega KK, Tokyo, Japan), according to the manufacturer's instructions. DNA concentrations were measured by Nano Drop ND-2000 (Thermo Fisher Scientific KK, Tokyo, Japan). The degradation of DNA was visually checked by electrophoresis on a $1 \%$ agarose gel, and the contamination of RNA was checked using the Qubit dsDNA BR Assay Kit (Thermo Fisher Scientific KK, Tokyo, Japan). 
Samples that filled the following criteria were used for further sequence analysis: Concentration $>20 \mathrm{ng} / \mu \mathrm{L}$; volume $\geq 20 \mu \mathrm{L} ; \mathrm{A} 260 / 280 \geq 1.8$; and A260/230 > 1.5. In this study, all samples passed these criteria.

\subsection{Microbial Community Analysis}

Extracted DNA was analyzed in the laboratory (Chun Lab, Seoul, Korea). Polymerase chain reaction (PCR) amplification was performed using primers specific to the V3-V4 region next-generation sequencing tags of the 16S rRNA gene in the extracted bacterial DNA. The taxonomic classification of each read was assigned based on a search of the EzBioCloud 16S database [28,29]. This database contains the $16 \mathrm{~S}$ rRNA genes of strains that have valid published names and representative species-level phylotypes of both cultured and uncultured entries in the GenBank database, with complete hierarchical taxonomic classification from the phylum to the species levels.

\subsection{Bioinformatics Analysis}

Children were divided into a caries-free group with no dental caries $(\mathrm{DMFS}=0)$ and a caries group (DMFS $>0$ ). The number of $16 \mathrm{~S}$ rRNA gene copies (absolute abundance) of operational taxonomic units (OTUs) was calculated by multiplying their respective relative abundance by the total number of $16 \mathrm{~S}$ rRNA gene copies.

For comparison of the two groups, after checking the normality of the values obtained by Kolmogorov-Smirnov tests, Mann Whitney's U test was applied. To visualize the characteristics of the species in terms of prevalence and abundance, principal component analysis (PCA) was carried out.

Bioinformatic analysis was performed using the Microbiome package on the Bioconductor of $R$ software (Ver. 3.61).

\subsection{Ethical Approval}

All 50 children who participated in the oral examination were approved for the purpose of this study. Prior to the oral exam, each child or guardian completed an informed consent form. This study was approved by the Ethical Committee of Tsurumi University School of Dental Medicine (Approval Number: 1624).

\section{Results}

From thirteen subjects, 263,458 valid reads were generated. From these valid reads, 640 operational taxonomic units (species) were detected when a $97 \%$ identity cut-off value was used.

The alpha diversity indices, Shannon, Simpson, Chao and ACE, were calculated to analyze the diversity and richness of the individual samples. The ACE, Chao1, Jack Knife, Shannon and Simpson were calculated to analyze the diversity and richness of all the samples. When comparing samples of the dental plaque and tongue, the indices of ACE, Chao1, Jack Knife and Shannon were not significantly different $(p>0.05)$, proving that the bacterial diversity and richness were similar in samples collected from the dental plaque and tongue. The mean values of these indices are shown in Table S1. A rarefaction curve is shown in Figure S1.

Figure 1 shows the relative abundance of the detected bacteria at the phylum level. Proteobacteria was the most abundant, followed by Firmicutes and Bacteroides. Others included Saccharibacteria (formerly known as TM7), Spirochetes, Synergistetes, SR1, Peregrinibacteria, Tenericutes, Chloroflexi and unclassified organisms in a higher taxonomic rank.

The heat map constructed from whole reads is shown in Figure 2. By clustering, subjects C5 and H1 were separated; however, seven subjects with dental caries and six subjects with dental caries were separated. 


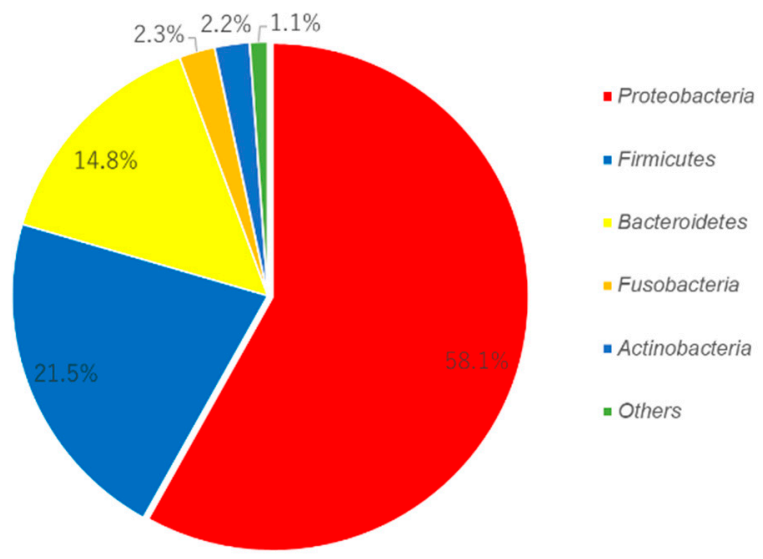

Figure 1. Abundance of the oral microbiome of the 13 subjects at the phylum level.

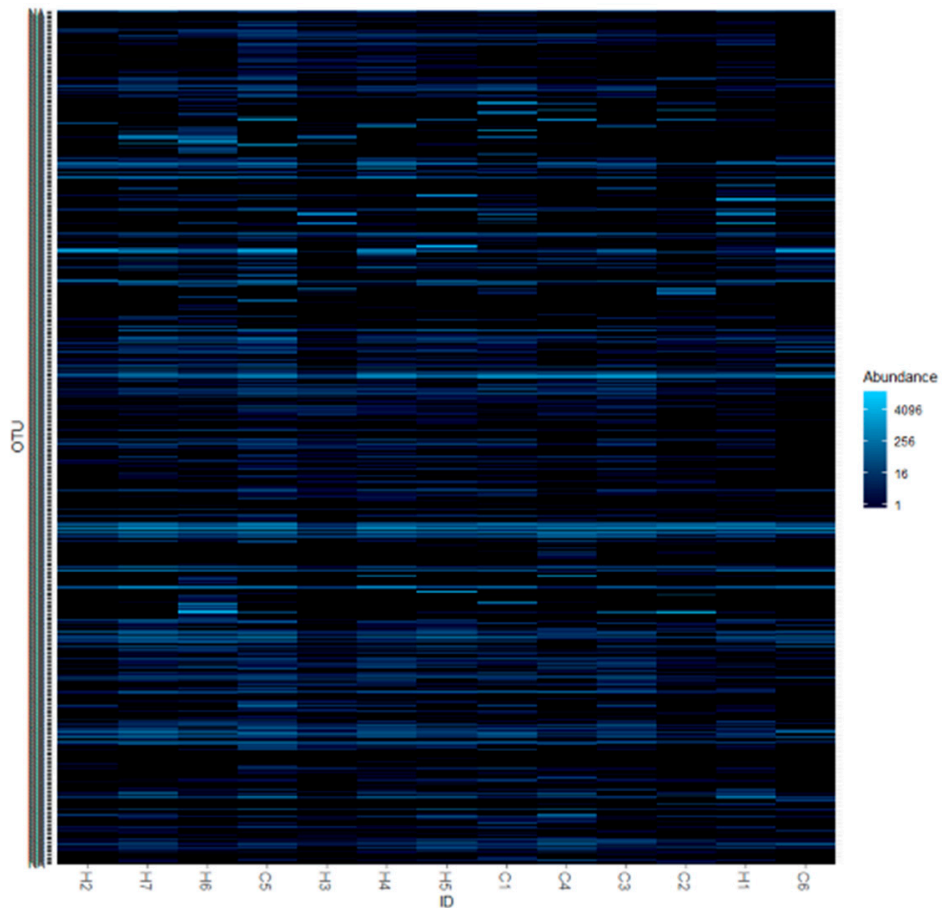

Figure 2. Heat map constructed from whole reads from 13 subjects.

\subsection{Candidate for the Core Microbiome}

From 13 subjects, 44 bacteria were detected. A list of these bacteria is shown in Table 1. These bacteria were candidates for the core microbiome of the human oral cavity; however, some of the pathogenic bacteria were included.

Table 1. A list of the bacteria found in samples from all thirteen subjects.

\begin{tabular}{cc}
\hline Taxon Name & Abundance (\%) \\
\hline Veillonella parvula group & $5.22 \%(0.48-21.92 \%)$ \\
Neisseria sicca group & $4.72 \%(0.09-31.89 \%)$ \\
Streptococcus pneumoniae group & $4.40 \%(0.37-8.80 \%)$ \\
Haemophilus parainfluenzae group & $3.60 \%(0.21-8.34 \%)$ \\
Lautropia mirabilis & $2.99 \%(0.27-9.79 \%)$ \\
Streptococcus sanguinis group & $1.89 \%(0.18-4.00 \%)$ \\
Veillonella dispar & $1.78 \%(0.03-7.47 \%)$ \\
Streptococcus parasanguinis group & $1.24 \%(0.15-2.89 \%)$ \\
Granulicatella adiacens group & $0.99 \%(0.05-3.57 \%)$ \\
\hline
\end{tabular}


Table 1. Cont.

\begin{tabular}{|c|c|}
\hline Taxon Name & Abundance (\%) \\
\hline Aggregatibacter aphrophilus & $0.92 \%(0.02-5.49 \%)$ \\
\hline Fusobacterium nucleatum group & $0.74 \%(0.07-1.55 \%)$ \\
\hline Veillonella rogosae & $0.72 \%(0.02-3.17 \%)$ \\
\hline Porphyromonas pasteri & $0.72 \%(0.01-2.35 \%)$ \\
\hline Streptococcus peroris group & $0.61 \%(0.03-1.30 \%)$ \\
\hline Gemella morbillorum & $0.57 \%(0.02-2.05 \%)$ \\
\hline Leptotrichia buccalis group & $0.54 \%(0.02-1.97 \%)$ \\
\hline Aggregatibacter segnis & $0.54 \%(0.01-1.63 \%)$ \\
\hline Capnocytophaga granulosa & $0.47 \%(0.04-1.49 \%)$ \\
\hline Streptococcus gordonii group & $0.46 \%(0.04-2.15 \%)$ \\
\hline Prevotella loescheii & $0.46 \%(0.03-2.12 \%)$ \\
\hline Abiotrophia defectiva & $0.41 \%(0.01-1.40 \%)$ \\
\hline Capnocytophaga sputigena & $0.39 \%(0.02-1.27 \%)$ \\
\hline KI259256_s & $0.36 \%(0.02-1.90 \%)$ \\
\hline Streptococcus_uc & $0.36 \%(0.01-0.90 \%)$ \\
\hline Streptococcus sinensis group & $0.34 \%(0.03-1.07 \%)$ \\
\hline ADCM_s & $0.31 \%(0.02-0.54 \%)$ \\
\hline JQ463704_s & $0.28 \%(0.02-1.14 \%)$ \\
\hline Gemella haemolysans group & $0.25 \%(0.02-0.90 \%)$ \\
\hline Veillonella_uc & $0.24 \%(0.01-0.90 \%)$ \\
\hline CP017038_s & $0.22 \%(0.03-0.53 \%)$ \\
\hline Campylobacter gracilis & $0.21 \%(0.02-0.65 \%)$ \\
\hline Cardiobacterium hominis & $0.19 \%(0.02-0.40 \%)$ \\
\hline JF239777_s & $0.18 \%(0-0.98 \%)$ \\
\hline Unclassified in a higher taxonomic rank & $0.16 \%(0.03-0.45 \%)$ \\
\hline Streptococcus anginosus group & $0.16 \%(0.02-0.65 \%)$ \\
\hline Prevotella oris & $0.12 \%(0.01-0.50 \%)$ \\
\hline Actinomyces odontolyticus & $0.11 \%(0.01-0.47 \%)$ \\
\hline Corynebacterium matruchotii & $0.09 \%(0.01-0.51 \%)$ \\
\hline Dialister invisus & $0.09 \%(0.01-0.27 \%)$ \\
\hline Actinomyces oris & $0.08 \%(<0.01-0.29 \%)$ \\
\hline Granulicatella elegans & $0.07 \%(<0.01-0.23 \%)$ \\
\hline Campylobacter concisus group & $0.07 \%(0.02-0.16 \%)$ \\
\hline Actinomyces naeslundii & $0.06 \%(<0.01-0.21 \%)$ \\
\hline Prevotella maculosa & $0.06 \%(<0.01-0.13 \%)$ \\
\hline
\end{tabular}

\subsection{Difference in the Oral Microbiome between Subjects with or without Dental Caries}

Figure 3 shows a comparison of the oral bacterial composition of subjects with or without dental caries. For the subjects without dental caries, Proteobacteria was abundant. In contrast, for subjects with dental caries, Firmicutes and Bacteroides were abundant. The proportions of phyla of each subject that participated in this study are shown in Figure S2. There were four subjects with a proportion of Proteobacteria lower than 40\% (Sample ID: H6, C2, C3, and C4). For two subjects (Sample ID: H6 and C2), Bacteroides was abundant, while for another two subjects (C3 and C4), Firmicutes was abundant. These two subjects had dental caries.

The proportions of Firmicutes and Proteobacteria at the genus level are shown in Figure S3. For Firmicutes, organic acid-related bacteria (Streptococcus and Veillonella) were more prevalent in subjects with dental caries. Granulicatella, Gemella, Abiotrophia and Bacillus exhibited a higher prevalence in subjects without dental caries. Proteobacteria, Neisseria, Pseudomonas and Acinetobactor were more prevalent in subjects with dental caries, whilst Aeromonas was more prevalent in subjects without dental caries. 
(A)

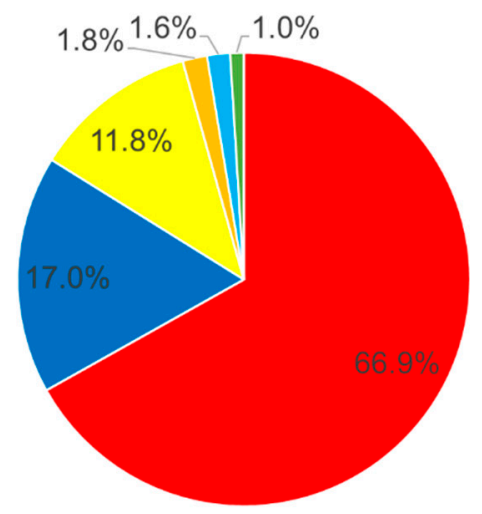

(B)

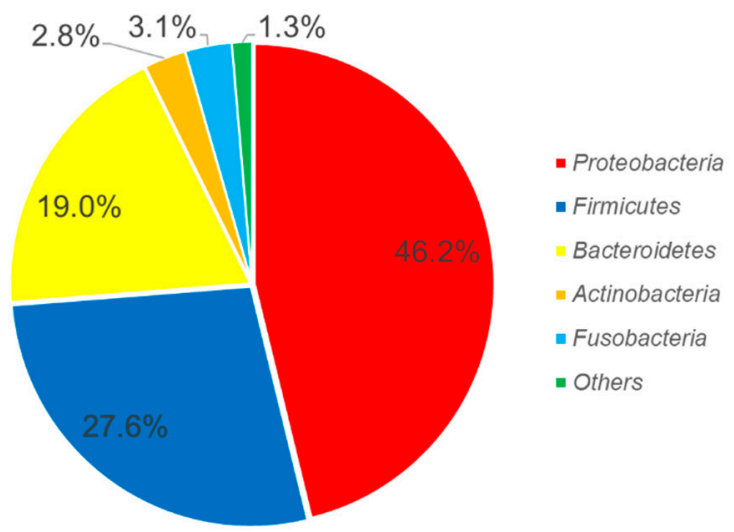

Figure 3. Comparison of the oral bacterial composition of subjects with or without dental caries. (A) Subjects without dental caries, and (B) subjects with dental caries.

Table 2 shows the bacteria that displayed statistically significant differences between subjects with or without dental caries. The Lactobacillus mucosae, Neisseria bacilliformis, Parascardovia denticolens, Prevotella multisaccharivorax, Pseudomonas uc and Staphylococcus sciuri groups were not detected in subjects without dental caries. Veillonella dispar was not a cariogenic organism. However, it was abundant in the subjects with dental caries. Members of Veillonella obtain energy from the utilization of organic acids. Therefore, they may have been isolated from cariogenic circumstances where organic acids were dominant.

Table 2. The significantly different bacteria between subjects with or without dental caries at the species level.

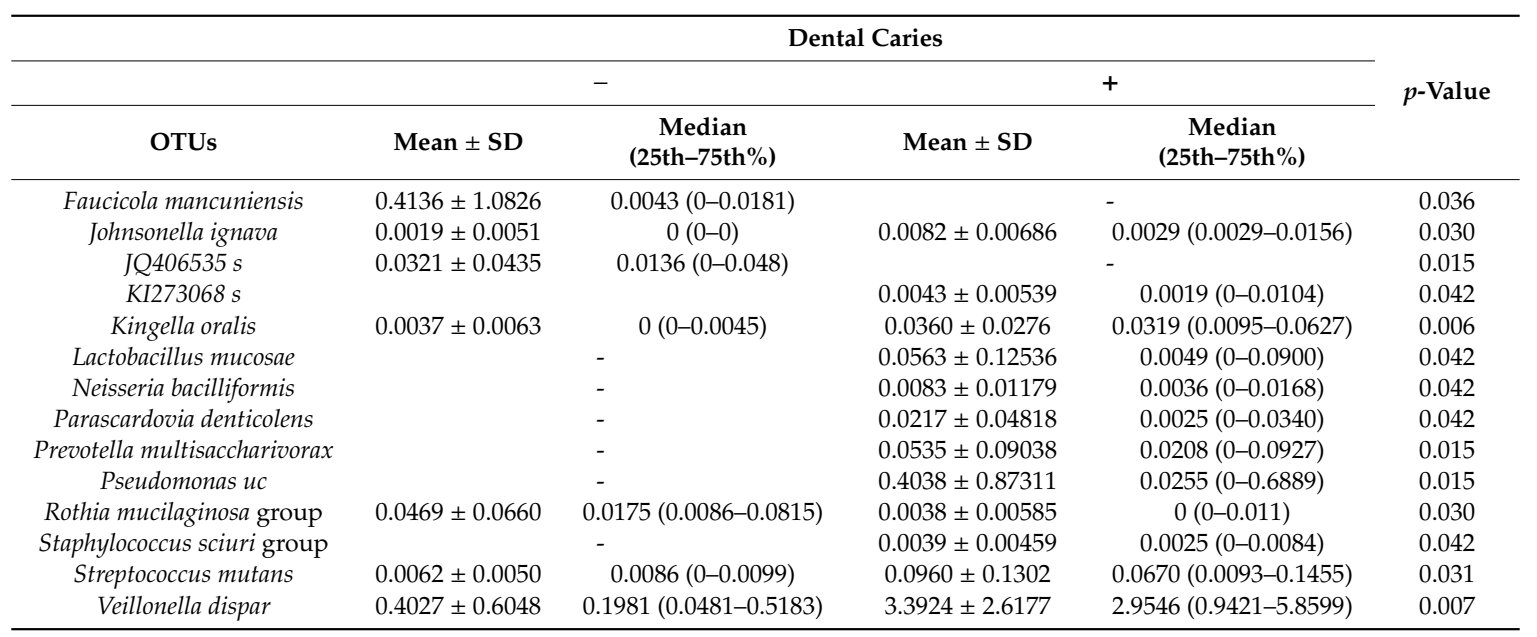

- No dental caries; + With dental caries.

The well-known major cariogenic bacteria Streptococcus mutans was included; however, Streptococcus sobrinus was not included. Streptococcus sobrinus was not detected in any of the subjects that participated in this study.

The well-known major cariogenic bacteria Streptococcus mutans was more prevalent in subjects with dental caries. However, Streptococcus sobrinus was not detected in either group.

Figure 4 shows the results of the principal component analysis of the significantly different bacteria between subjects with or without dental caries at the species level. Prevotella multisaccharivorax, Neisseria bacilliformis, Lactobacillus mucosae and Parascardovia denticolens were located near Streptococcus mutans. Pseudomonas uc and Veillonella dispar were located near each other. For the subjects without dental caries, 
Proteobacteria was abundant. In contrast, for subjects with dental caries, Firmicutes and Bacteroides were abundant.

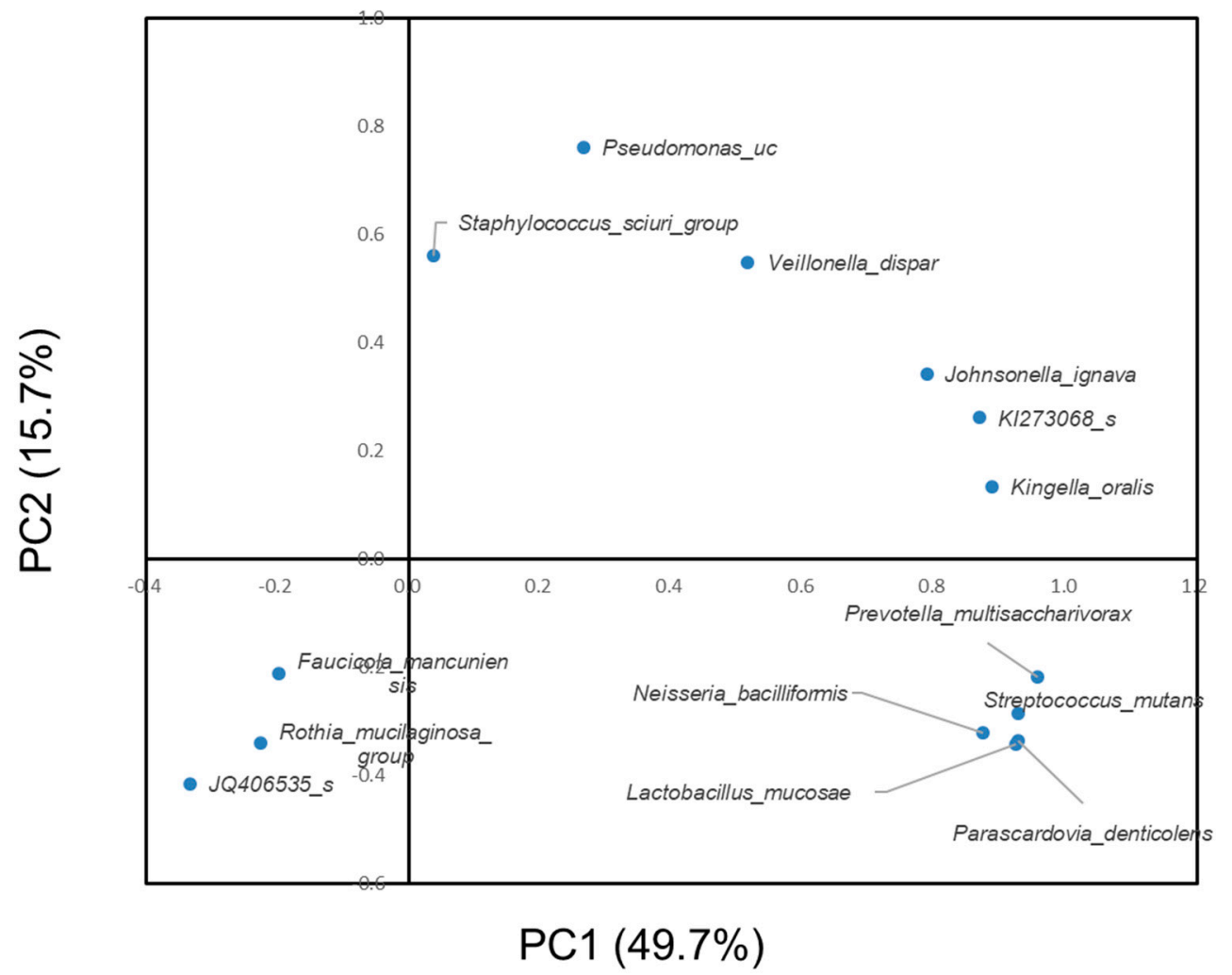

Figure 4. Principal component analysis of the significantly different bacteria between subjects with or without dental caries at the species level.

\section{Discussion}

In this study, the oral microbiome of 13 children of mountain people living in the Chin state of Myanmar was analyzed, with respect to the core oral microbiome and etiology of dental caries. Proteobacteria was the major component of the oral microbiome profile. Several species, including Streptococcus mutans, exhibited statistically significant differences in the abundance of dental plaque of children with or without dental caries.

Several studies have shown that in a healthy oral cavity, $96 \%$ of the total oral bacteria can be categorized as Firmicutes, Actinobacteria, Proteobacteria, Fusobacteria, Bacteroides and Spirochetes [15,30-32]. The majority of bacteria in a healthy oral cavity is Firmicutes, where different species of Streptococci are exhibited, with the most abundant being cocci $[33,34]$. The site-specific nature of the oral microbiome has been suggested [35]. In dental plaque, Firmicutes and Actinobacteria are known to be abundant [2]. In contrast to this, Proteobacteria were abundant in this study (Figure 1). Proteobacteria is suggested to be abundant in the oral cavity, following Firmicutes and Bacteroidetes [36].

It has been suggested that environmental exposure changes the oral microbiome throughout one's life $[37,38]$. Food consumption patterns and contact with exogenous bacteria in food, water, air, other people and domestic animals have been suggested to change the oral microbiome [38,39]. In particular, Western food played a role in the emergence of modern oral pathogens [40]. Oral hygiene habits may play an important role in changing the oral microbiome. The microbial community differs between childhood and adulthood [41,42]. A study which investigated the oral microbiome of infants concluded that the major microbiome consisted of six phyla: Firmicutes; Proteobacteria; Actinobacteria; Bacteroides; Fusobacteria; and Spirochaetes [38]. Firmicutes were the most abundant, followed by Proteobacteria. 
Another study in Estonia that investigated ninety Estonian schoolchildren (11.3 \pm 0.6 years) recorded the presence of Firmicutes (39.1\%), Proteobacteria (26.1\%), Bacteroidetes (14.7\%), Actinobacteria (12\%) and Fusobacteria (6\%) [43].

Another study in China investigated 40 young children (age 6-8) with mixed dentition. Seven major phyla ( $>95 \%$ of all sequences) were recorded, including Firmicutes (plaque: 27\%; saliva: $64 \%$ ), Bacteriodetes (plaque: 29\%; saliva: 13\%), Proteobacteria (plaque: 18\%; saliva: $11 \%$ ), Fusobacteria (plaque: 19\%; saliva: 3\%), Actinobacteria (plaque: 3\%; saliva: $8 \%$ ), Saccharibacteria (TM7) (plaque: $1.5 \%$; saliva: 0.5\%) and Spirochaetes (plaque: 0.59\%; saliva: 0.065\%). Firmicutes, Bacteroides and Fusobacteria occupied more than $70 \%$ of the oral microbiome of the subjects with mixed dentition. Additionally, Proteobacteria had a prevalence of less than 20\% [44]. Our results showed that Proteobacteria was the most abundant bacteria in our sample set, due to ethnic- or isolated community-level differences investigated in previous reports [45,46].

The proportion of Firmicutes was higher in children with dental caries (Figure 3). Streptococcus mutans and lactobacilli belonging to the phylum Firmicutes were major cariogenic bacteria [47].

According to the results of the principal component analysis, the species Lactobacillus mucosae, Neisseria bacilliformis, Parascardovia denticolens and Prevotella multisaccharivorax were located near S. mutans (Figure 4). Furthermore, these four species were detected in subjects with dental caries and not detected in subjects without dental caries (Table 2). Therefore, there is a possibility that they have a nature similar to the cariogenic bacteria S. mutans.

The existence of restorations affects oral microbiome profiles. It is well-known that resin monomers have a biological effect on human immune system cells [48], and may disturb the oral microbiome profile. In this study, however, no children had restated teeth or orthodontic appliances in their oral cavity. Pit and fissure sealant is an effective tool for the prevention of dental caries [49]. Dental materials employed for the prevention of dental caries also disturb oral microbiome profiles. Materials used for pit and fissure sealant contain resin monomer and fluoride, and fluoride affects streptococci [50]. In the mountainous area of this study, many children do not use toothpaste, and there are no fluoride mouth rinse prevention programs. Additionally, no children had pit and fissure sealant. In this study, dental materials may have little or no effect on the microbiome profile.

Diet plays an important role in dental caries. S. mutans produces lactic acid under anaerobic conditions. In addition, other acidic metabolites, such as formate and acetate ethanol, are produced [51]. Under this environment, acidophilic bacteria such as lactobacilli favor growth in the oral cavity. Acid production by an excess uptake of carbohydrates results in dental caries [52]. The carbohydrate-rich modern diet may act as an environmental factor, causing changes that increase the cariogenicity of the oral microbiome. In this study, the oral microbiome of the children with dental caries showed a similar pattern to the microbiome of adults in other studies [37].

The limitations of this study were the small sample size, and the fact that only dental plaque samples were analyzed. Moreover, we only investigated one area of Myanmar, where more than 150 ethnic groups live. As the daily food intake affects the microbiome, nutrients of local food should be analyzed and compared with the oral microbiome. Defining the core microbiome requires further studies to investigate a wider ethnic group and larger sample size.

\section{Conclusions}

In the oral microbiome of the children living in the isolated area of this study, the most abundant phylum was Proteobacteria. The oral microbiome may be affected by environmentaland community-level factors. The oral microbiomes were different between children with or without dental caries. The composition of the oral microbiome may thus affect the risk of dental caries.

Supplementary Materials: The following are available online at http://www.mdpi.com/1660-4601/17/11/4033/s1, Table S1: Alpha diversity indices of different groups; Figure S1: Rarefaction curve Figure S2: Proportion of phyla of each subject; Figure S3: Proportion of Firmicutes at the genus level and proportion of Proteobacteria at the genus level, OUT data and sequencing data. 
Author Contributions: Y.N. and R.O. visited Myanmar and performed the oral examination. Y.N. wrote the manuscript. Y.N., R.O., R.H. and N.H. designed the research study and coordinated data collection. Y.N. performed the data management and statistical analyses. R.H. and N.H. provided technical advice and critically reviewed the manuscript. Funding was acquired by Y.N. and N.H. All authors were involved in project management and contributed to the drafting of the journal article. All authors have read and agreed to the published version of the manuscript.

Funding: This study was supported by JSPS KAKENHI (Grant Number: 17K12030, 20K10303) and was partially supported by SECOM Science and Technology Foundation. None of the funders played a role in the design of the study, data collection or analyses, interpretation of the results or writing of the manuscript.

Conflicts of Interest: The authors declare no conflict of interest. The funders had no role in the design of the study; in the collection, analyses, or interpretation of data; in the writing of the manuscript, or in the decision to publish the results.

\section{References}

1. Aas, J.A.; Paster, B.J.; Stokes, L.N.; Olsen, I.; Dewhirst, F.E. Defining the normal bacterial flora of the oral cavity. J. Clin. Microbiol. 2005, 43, 5721-5732. [CrossRef]

2. Keijser, B.J.; Zaura, E.; Huse, S.M.; van der Vossen, J.M.; Schuren, F.H.; Montijn, R.C.; ten Cate, J.M.; Crielaard, W. Pyrosequencing analysis of the oral microflora of healthy adults. J. Dent. Res. 2008, 87, 1016-1020. [CrossRef]

3. Wade, W.G. The oral microbiome in health and disease. Pharmacol. Res. 2013, 69, 137-143. [CrossRef]

4. Costalonga, M.; Herzberg, M.C. The oral microbiome and the immunobiology of periodontal disease and caries. Immunol. Lett. 2014, 162, 22-38. [CrossRef] [PubMed]

5. Greenwood, D.; Afacan, B.; Emingil, G.; Bostanci, N.; Belibasakis, G.N. Salivary Microbiome Shifts in Response to Periodontal Treatment Outcome. Proteom. Clin. Appl. 2020, 29, e2000011. [CrossRef] [PubMed]

6. Sampaio-Maia, B.; Caldas, I.M.; Pereira, M.L.; Pérez-Mongiovi, D.; Araujo, R. The Oral Microbiome in Health and Its Implication in Oral and Systemic Diseases. Adv. Appl. Microbiol. 2016, 97, 171-210. [CrossRef] [PubMed]

7. Patini, R. Oral Microbiota: Discovering and Facing the New Associations with Systemic Diseases. Pathogens 2020, 9, 313. [CrossRef] [PubMed]

8. Grusell, E.N.; Dahlén, G.; Ruth, M.; Bergquist, H.; Bove, M. The Cultivable Bacterial Flora of the Esophagus in Subjects with Esophagitis. Scand. J. Gastroenterol. 2018, 53, 650-656. [CrossRef]

9. Olsen, I.; Hicks, S.D. Oral Microbiota and Autism Spectrum Disorder (ASD). J. Oral Microbiol. 2019, 12, 1702806. [CrossRef]

10. Bars, P.L.; Matamoros, S.; Montassier, E.; Vacon, F.L.; Potel, G.; Soueidan, A.; Jordana, F.; Cochetière, M.F.L. The Oral Cavity Microbiota: Between Health, Oral Disease, and Cancers of the Aerodigestive Tract. Can. J. Microbiol. 2017, 63, 475-492. [CrossRef]

11. Gao, L.; Xu, T.; Huang, G.; Jiang, S.; Gu, Y.; Chen, F. Oral Microbiomes: More and More Importance in Oral Cavity and Whole Body. Protein Cell. 2018, 9, 488-500. [CrossRef]

12. Krishnan, K.; Chen, T.; Paster, B.J. A Practical Guide to the Oral Microbiome and Its Relation to Health and Disease. Oral Dis. 2017, 3, 276-286. [CrossRef]

13. Segata, N.; Haake, S.K.; Mannon, P.; Lemon, K.P.; Waldron, L.; Gevers, D.; Huttenhower, C.; Izard, J. Composition of the adult digestive tract bacterial microbiome based on seven mouth surfaces, tonsils, throat and stool samples. Genome Biol. 2012, 13, R42. [CrossRef] [PubMed]

14. Griffen, A.L.; Beall, C.J.; Firestone, N.D.; Gross, E.L.; Difranco, J.M.; Hardman, J.H.; Vriesendorp, B.; Faust, R.A.; Janies, D.A.; Leys, E.J. CORE: A phylogenetically-curated 16S rDNA database of the core oral microbiome. PLoS ONE 2011, 6, e19051. [CrossRef] [PubMed]

15. Zaura, E.; Keijser, B.J.; Huse, S.M.; Crielaard, W. Defining the healthy "core microbiome" of oral microbial communities. BMC Microbiol. 2009, 9, 259. [CrossRef] [PubMed]

16. Li, J.; Quinque, D.; Horz, H.P.; Li, M.; Rzhetskaya, M.; Raff, J.A.; Hayes, M.G.; Stoneking, M. Comparative analysis of the human saliva microbiome from different climate zones: Alaska Germany and Africa. BMC Microbiol. 2014, 14, 316. [CrossRef] [PubMed]

17. Takeshita, T.; Matsuo, K.; Furuta, M.; Shibata, Y.; Fukami, K.; Shimazaki, Y.; Akifusa, S.; Han, D.H.; Kim, H.D.; Yokoyama, T.; et al. Distinct composition of the oral indigenous microbiota in South Korean and Japanese adults. Sci. Rep. 2014, 4, 6990. [CrossRef] [PubMed] 
18. Myint, Z.C.K.; Zaitsu, T.; Oshiro, A.; Ueno, M.; Soe, K.K.; Kawaguchi, Y. Risk Indicators of Dental Caries and Gingivitis Among 10-11-year-old Students in Yangon, Myanmar. Int. Dent. J. 2019. [CrossRef]

19. Phyo, A.Z.Z.; Chansatitporn, N.; Narksawat, K. Oral Health Status and Oral Hygiene Habits Among Children Aged 12-13 Years in Yangon, Myanmar. Southeast. Asian J. Trop. Med. Public Health 2013, 44, 1108-1114.

20. Chu, C.H.; Chau, A.M.; Wong, Z.S.; Hui, B.S.; Lo, E.C. Oral Health Status and Behaviours of Children in Myanmar-A Pilot Study in Four Villages in Rural Areas. Oral Health Prev. Dent. 2012, 10, 365-371.

21. Nomura, Y.; Maung, K.; Khine, E.M.K.; Sint, K.M.; Lin, M.P.; Myint, M.K.W.; Aung, T.; Sogabe, K.; Otsuka, R.; Okada, A.; et al. Prevalence of Dental Caries in 5- and 6-Year-Old Myanmar Children. Int. J. Dent. 2019, 2019, 5948379. [CrossRef] [PubMed]

22. Gross, E.L.; Beall, C.J.; Kutsch, S.R.; Firestone, N.D.; Leys, E.J.; Griffen, A.L. Beyond Streptococcus mutans: Dental caries onset linked to multiple species by $16 \mathrm{~S}$ rRNA community analysis. PLoS ONE 2012, 7, e47722. [CrossRef] [PubMed]

23. Hughes, T.; Bockmann, M.; Townsend, G.; Salehi, H.; Adler, C.J. Preliminary study of the oral mycobiome of children with and without dental caries. J. Oral Microbiol. 2018, 11, 1536182. [CrossRef]

24. Hurley, E.; Barrett, M.P.J.; Kinirons, M.; Whelton, H.; Ryan, C.A.; Stanton, C.; Harris, H.M.B.; O'Toole, P.W. Comparison of the salivary and dentinal microbiome of children with severe-early childhood caries to the salivary microbiome of caries-free children. BMC Oral Health 2019, 19, 13. [CrossRef] [PubMed]

25. World Health Organization. Oral Health Surveys: Basic Methods, 5th ed.; WHO: Geneva, Switzerland, 2013.

26. Okada, M.; Hayashi, F.; Nagasaka, N. PCR detection of 5 Putative periodontal pathogens in dental plaque samples from children 2 to 12 years of age. J. Clin. Periodontol. 2001, 28, 576-582. [CrossRef] [PubMed]

27. Okada, A.; Sogabe, K.; Takeuchi, H.; Okamoto, M.; Nomura, Y.; Hanada, N. Characterization of specimens obtained by different sampling methods for evaluation of periodontal bacteria. J. Oral Sci. 2017, 59, 491-498. [CrossRef] [PubMed]

28. Kim, O.S.; Cho, Y.J.; Lee, K.; Yoon, S.H.; Kim, M.; Na, H.; Park, S.C.; Jeon, Y.S.; Lee, J.H.; Yi, H.; et al. Introducing EzTaxon-e: A prokaryotic 16S rRNA gene sequence database with phylotypes that represent uncultured species. Int. J. Syst. Evol. Microbiol. 2012, 62, 716-721. [CrossRef] [PubMed]

29. Yoon, S.H.; Ha, S.M.; Kwon, S.; Lim, J.; Kim, Y.; Seo, H.; Chun, J. Introducing EzBioCloud: A taxonomically united database of 16S rRNA and whole genome assemblies. Int. J. Syst. Evol. Microbiol. 2017, 67, 1613-1617. [CrossRef] [PubMed]

30. Verma, D.; Garg, P.K.; Dubey, A.K. Insights into the human oral microbiome. Arch. Microbiol. 2018, 200, 525-540. [CrossRef]

31. Bik, E.M.; Long, C.D.; Armitage, G.C.; Loomer, P.; Emerson, J.; Mongodin, E.F.; Nelson, K.E.; Gill, S.R.; Fraser-Liggett, C.M.; Relman, D.A. Bacterial diversity in the oral cavity of 10 healthy individuals. ISME J. 2010, 4, 962-974. [CrossRef]

32. Palmer, R.J. Composition and development of oral bacterial com-munities. Periodontol. 2000 2014, 64, 20-39. [CrossRef] [PubMed]

33. Dewhirst, F.E.; Chen, T.; Izard, J.; Paster, B.J.; Tanner, A.C.; Yu, W.H.; Lakshmanan, A.; Wade, W.G. The human oral microbiome. J. Bacteriol. 2010, 192, 5002-5017. [CrossRef] [PubMed]

34. Mager, D.L.; Haffajee, A.D.; Devlin, P.M.; Norris, C.M.; Posner, M.R.; Goodson, J.M. The salivary microbiota as a diagnostic indicator of oral cancer: A descriptive non-randomized study of cancer-free and oral squamous cell carcinoma subjects. J. Transl. Med. 2005, 3, 27. [CrossRef] [PubMed]

35. Shi, W.; Tian, J.; Xu, H.; Zhou, Q.; Qin, M. Distinctions and associations between the microbiota of saliva and supragingival plaque of permanent and deciduous teeth. PLoS ONE 2018, 13, e0200337. [CrossRef]

36. Kersters, K.; Lisdiyanti, P.; Kmagata, K.; Swings, J. The Family Acetobacteracea: The Genera Acetobacter; Acidomonas; Asaia; Gluconacetobacter; Gluconobacter; and Kozakia. In The Prokaryotes; Dworkin, M., Falkow, S., Rosenberg, E., Eds.; Springer: New York, NY, USA, 2006; Volume 5, pp. 163-200.

37. Sampaio-Maia, B.; Monteiro-Silva, F. Acquisition and maturation of oral microbiome throughout childhood: An update. Dent. Res. J. (Isfahan) 2014, 11, 291-301.

38. Cephas, K.D.; Kim, J.; Mathai, R.A.; Barry, K.A.; Dowd, S.E.; Meline, B.S.; Swanson, K.S. Comparative analysis of salivary bacterial microbiome diversity in edentulous infants and their mothers or primary care givers using pyrosequencing. PLOS ONE 2011, 6, e23503. [CrossRef]

39. Shi, W.; Qin, M.; Chen, F.; Xia, B. Supragingival Microbial Profiles of Permanent and Deciduous Teeth in Children with Mixed Dentition. PLoS ONE 2016, 11, e0146938. [CrossRef] [PubMed] 
40. Lassalle, F.; Spagnoletti, M.; Fumagalli, M.; Shaw, L.; Dyble, M.; Walker, C.; Thomas, M.G.; Migliano, A.B.; Balloux, F. Oral microbiomes from hunter-gatherers and traditional farmers reveal shifts in commensal balance and pathogen load linked to diet. Mol. Ecol. 2018, 27, 182-195. [CrossRef] [PubMed]

41. Xu, X.; He, J.; Xue, J.; Wang, Y.; Li, K.; Zhang, K.; Guo, Q.; Liu, X.; Zhou, Y.; Cheng, L.; et al. Oral cavity contains distinct niches with dynamic microbial communities. Environ. Microbiol. 2015, 17, 699-710. [CrossRef] [PubMed]

42. Crielaard, W.; Zaura, E.; Schuller, A.A.; Huse, S.M.; Montijn, R.C.; Keijser, B.J. Exploring the oral microbiota of children at various developmental stages of their dentition in the relation to their oral health. BMC Med. Genom. 2011, 4, 22. [CrossRef]

43. Štšepetova, J.; Truu, J.; Runnel, R.; Nõmmela, R.; Saag, M.; Olak, J.; Nõlvak, H.; Preem, J.K.; Oopkaup, K.; Krjutškov, K.; et al. Impact of polyols on Oral microbiome of Estonian schoolchildren. BMC Oral Health. 2019, 19, 60. [CrossRef]

44. Xu, Y.; Jia, Y.H.; Chen, L.; Huang, W.M.; Yang, D.Q. Metagenomic analysis of oral microbiome in young children aged 6-8 years living in a rural isolated Chinese province. Oral Dis. 2018, 24, 1115-1125. [CrossRef]

45. Gao, X.; Jiang, S.; Koh, D.; Hsu, C.Y. Salivary biomarkers for dental caries. Periodontol. 2000 2016, 70, $128-141$. [CrossRef] [PubMed]

46. Pagano, S.; Rabbit, M.; Valenti, C.; Negri, P.; Lombardo, G.; Costanzi, E.; Cianetti, S.; Montaseri, A.; Marinucci, L. Biological effects of resin monomers on oral cell populations: Descriptive analysis of literature. Eur. J. Paediatr. Dent. 2019, 20, 224-232. [CrossRef] [PubMed]

47. Bromo, F.; Guida, A.; Santoro, G.; Peciarolo, M.R.; Eramo, S. Pit and Fissure Sealants: Review of Literature and Application Technique. Minerva Stomatol. 2011, 60, 529-541.

48. Bunick, F.J.; Kashket, S. Enolases from fluoride-sensitive and fluoride-resistant streptococci. Infect. Immun. 1981, 34, 856-863. [CrossRef] [PubMed]

49. Yamada, T.; Takahashi-Abbe, S.; Abbe, K. Effects of oxygen on pyruvate formate-lyase in situ and sugar metabolism of Streptococcus mutans and Streptococcus sanguis. Infect. Immun. 1985, 47, 129-134. [CrossRef]

50. Nyvad, B.; Kilian, M. Microbiology of the early colonization of human enamel and root surfaces in vivo. Eur. J. Oral Sci. 1987, 95, 369-380. [CrossRef]

51. Sharma, N.; Bhatia, S.; Sodhi, A.S.; Batra, N. Oral microbiome and health. AIMS Microbiol. 2018, 4, 42-66. [CrossRef]

52. Zachary, D.; Moye, L.Z.; Robert, A.B. Fueling the caries process: Carbohydrate metabolism and gene regulation by Streptococcus mutans. J. Oral Microbiol. 2014, 6, 24878. [CrossRef] 